\title{
Experimental study on the rheological behaviour of debris flow material in the Campania region
}

\author{
A. Scotto di Santolo, A. M. Pellegrino \& A. Evangelista \\ Department of Hydraulic, Geotechnical and Environmental Engineering, \\ University of Naples "Federico II", Italy
}

\begin{abstract}
The rheological behaviour of the natural material collected in the source area of three debris flows occurring in the mountainsides of the North-western Campania region (southern Italy) has been investigated. The tests have been carried out at different solid volumetric concentration $\mathrm{C}_{\mathrm{v}}$ with a standard rheometer equipped with two geometric configurations to avoid disturbing effects. All materials behave like a Non-Newtonian fluid with a threshold shear stress $\tau_{\mathrm{y}}$ (yield stress) that increases with solid volumetric concentration. The experimental data have been fitted with standard model generally used for fluids. A simple relation between $\mathrm{C}_{\mathrm{v}}$ and $\tau_{\mathrm{y}}$ has been obtained.

Keywords: rheology, debris flow, pyroclastic soils, laboratory activity, fluids model, yield stress.
\end{abstract}

\section{Introduction}

Debris flows represent serious hazards in slopes of the North-western Campania region (southern Italy). Therefore, the evaluation of constitutive laws for the material involved represents a key requirement for the hazard mitigation. Traditionally, debris flows have been regarded as homogeneous fluids and flow behaviour has been considered to be controlled by the properties of the 'matrix' (a mixture of fine sediment and water in which coarse particles are dispersed) $[1,2]$. Existing physical theories to describe flow and depositional process of debris flow are mainly divided into theories which are based on the treatment of material as one phase (rheological approaches) [3-6] or as two or more phases 
(Coulomb mixture approaches) [7, 8]. The Coulomb mixture approach specifies distinct constitutive equation for the solid phase, the liquid phase and the phase interaction force. Conversely, using a rheological approach, the bulk mixture behaviour can be characterized by a limited number of parameters, relating shear stress and viscosity to shear rate. The present study focuses the results from rheological point of view.

\section{Debris flow rheology}

Natural debris flows are often classified on the relative concentration of fine and coarse sediment that is used to characterize the main flow regime behaviour $[9,10]$. Above a critical solid concentration $\mathrm{C}_{\mathrm{v}}$, a particle-friction-collision regime dominates the flow process. Models based on the work of Bagnold [11] are used to describe the flow behaviour of these mixtures. If the solid concentration is less than the critical one, the flow behaves like Non-Newtonian fluids. They are also called time independent fluids and are subdivided into several groups (fig. 1). Generally, the debris flows mixtures behave like viscoplastic fluids, as indicated in curve (4), fig. 1. It is considered that, for such a fluid, exists an abrupt change in debris flows behaviour around a given shear stress value, the yield stress, which needs to be overcome before flow take place. The viscoplastic character of debris flow mixtures has often been reported in literature [4-6, 12-17]. Phenomenological laws like the Bingham generalized model are usually used to describe the rheological behaviour of these mixture $[6,10,18]$, which is written as:

$$
\tau=\tau_{y}+k \dot{\gamma}^{n}
$$

In eqn. (1), $\tau_{y}$ is the yield stress, $\dot{\gamma}$ is the shear rate, $k$ is the consistent coefficient and $n$ the pseudoplastic index. When the index $n$ is equal to the unity, the eqn. (1) becomes the Bingham model and the coefficient $k$ becomes the Bingham viscosity $\eta_{B}$ (curve (5) in fig. 1).

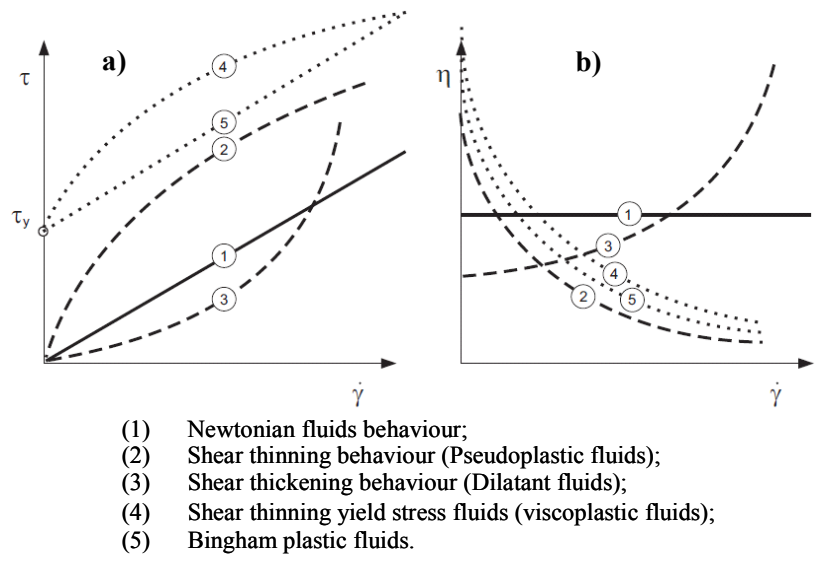

Figure 1: a) Flow curves; b) Viscosity curves. 


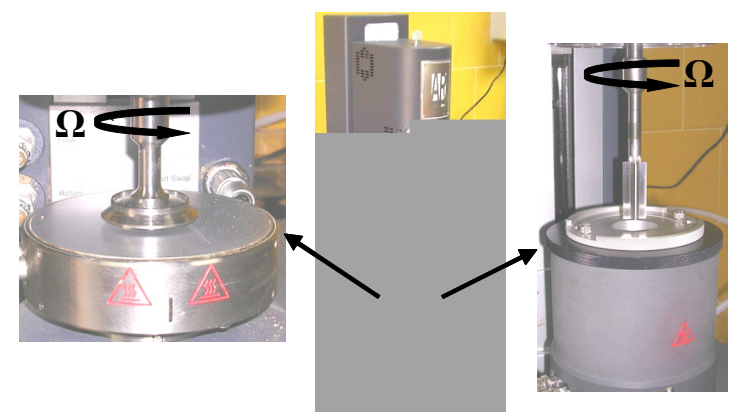

Figure 2: The rotational rheometer AR 2000ex (TA Instruments) and the two rheometrical system used: parallel plates and vane rotor system.

\section{Experimental setup and procedures}

\subsection{Rheometer apparatus}

In order to ensure the validity of rheometrical measurements and to reduce the risk of misinterpretation, the rotational rheometer AR 2000ex (TA Instruments) equipped with two different geometry systems (parallel plates - PP and vane rotor - VR) has been utilized (fig. 2). The parallel plates are composed of a lower stationary steel plate and an upper rotational one with a diameter of 40 $\mathrm{mm}$. The distance between two plates (the gap $H$ ) is larger than ten times maximum particles diameter, $d_{\max }[19]$. For a gap equal to $1 \mathrm{~mm}, d_{\max }$ must be smaller than $0.1 \mathrm{~mm}$. The shear rate and the shear stress are evaluated with following eqns:

$$
\begin{gathered}
\dot{\gamma}_{R}=\dot{\gamma}(R)=\frac{\Omega \cdot R}{H} \\
\tau\left(\dot{\gamma}_{R}\right)=\frac{3 \cdot T}{2 \cdot \pi \cdot R^{3}}+\frac{\dot{\gamma}_{R}}{2 \cdot \pi \cdot R^{3}} \cdot \frac{d T}{d \dot{\gamma}_{R}}
\end{gathered}
$$

where $r$ is the distance from the central axis, $R$ is the upper plates radius, $H$ is the gap, $\Omega$ is the rotation velocity ( $\mathrm{rad} / \mathrm{s}$ ) and $T$ is the torque.

The vane rotor geometry consists of four thin blades arranged at equal angles around a small cylindrical shaft: the blades radius is $14 \mathrm{~mm}$ and the blades height is $42 \mathrm{~mm}$. It is immersed in the sample (approximately equal to $27 \mathrm{ml}$ ) contained in a cylindrical cup with $15 \mathrm{~mm}$ in radius. The rotor is rotated around its axis at a given rotational speed $\Omega$ and the torque $T$ is measured by the transducer of the rheometer. During the test the material is trapped in the blades and the shear is achieved around a fictitious cylinder within the mixture [10]. The shear stress and shear rate are:

$$
\begin{aligned}
& \dot{\gamma}=\frac{\Omega \cdot R_{l}}{\left(R_{2}-R_{l}\right)} \\
& \tau=\frac{T}{2 \cdot \pi \cdot R_{l}^{2} \cdot L}
\end{aligned}
$$


where $R_{1}$ and $R_{2}$ are, respectively, the blades radius and the cup radius, $L$ is the material depth. The eqns. (4) and (5) are usually applied when the ratio $R_{1} / R_{2}$ is close to the unity.

\subsection{Materials}

The materials tested have been collected from the source area of three debris flows occurred in Campania region (southern Italy), fig. 3a). Material A has been sampled in Nocera, Salerno (March 2005). Material B in Monteforte Irpino, Avellino (May 1998). Material C in Astroni, Naples (December 2005). The soil type, involved in thickness of about a meter, regards the most recent pyroclastic deposits deriving from the volcanic activity of mount Somma/Vesuvius for materials $\mathrm{A}$ and $\mathrm{B}$ and from the volcanic activity of the Phlegrean Fields for material $C$. The grain size distributions of the samples are reported in fig. 3b). Soil A and soil B are sandy silt with a small clay fraction and soil $\mathrm{C}$ is gravely silty sand. These materials are well documented in the literature [20-22]. The substratum underlying the soil is of the same volcanic nature for material $\mathrm{C}$ and of a carbonatic nature for materials $\mathrm{A}$ and $\mathrm{B}$. Mean physical properties are reported in table $2\left(\mathrm{G}_{\mathrm{S}}\right.$ is the specific gravity of soil particles, $\gamma_{\mathrm{d}}$ and $\gamma$ are the dry and total weight of soil per unit volume respectively, $n$ is the porosity and $S_{r}$ is the degree of saturation).

Table 1: $\quad$ Main physical properties of the tested debris flow materials.

\begin{tabular}{|c|c|c|c|c|c|c|c|}
\hline Debris flow & Substratum & Material & $\mathrm{G}_{\mathrm{S}}$ & $\begin{array}{c}\gamma_{\mathrm{d}} \\
\left(\mathrm{Kn} / \mathrm{m}^{3}\right)\end{array}$ & $\begin{array}{c}\gamma \\
\left(\mathrm{Kn} / \mathrm{m}^{3}\right)\end{array}$ & $\mathrm{n}$ & $\mathrm{S}_{\mathrm{r}}$ \\
\hline Nocera & Carbonatic & $\mathrm{A}$ & 2.62 & 9.08 & 11.35 & 0.66 & 0.35 \\
\hline Monteforte Irpino & Carbonatic & $\mathrm{B}$ & 2.57 & 7.11 & 12.11 & 0.71 & 0.71 \\
\hline Astroni & Pyroclastic & $\mathrm{C}$ & 2.54 & 8.99 & 9.84 & 0.67 & 0.24 \\
\hline
\end{tabular}

\subsection{Laboratory procedures}

The analyzed debris flow mixtures have been tested in rate-controlled mode at constant temperature $\left(20 \pm 0.5^{\circ} \mathrm{C}\right)$. The flow curves have been determined during one experiment by applying successive shear rate level, ranging from 0.014 to $1400 \mathrm{~s}^{-1}$. In order to certify the reproducibility of the test, each one has been repeated at least three times and the averaged values of the experimental results have been considered. Due to the geometry dimension of the used rheometer, only the flow curves of material samples with grain sizes smaller than $0.1 \mathrm{~mm}$ have been derived. The experiments have been carried out with mixtures of different water content. The solid volumetric concentration $\mathrm{C}_{\mathrm{v}}$, i.e. the ratio of the amount of solids to the total mixture, has been considered. The total solid volumetric concentration $\mathrm{C}_{\mathrm{v}}$ is defined as:

$$
C_{v}=\frac{V_{s}}{V_{s}+V_{w}}
$$

where $\mathrm{V}_{\mathrm{w}}$ and $\mathrm{V}_{\mathrm{s}}$ are, respectively, the volume of water and solid in the sample. In order to consider a significant range of the sediment concentration for the material tested, mixtures with $\mathrm{C}_{\mathrm{v}}$ changing from 0.20 to 0.40 have been prepared. 


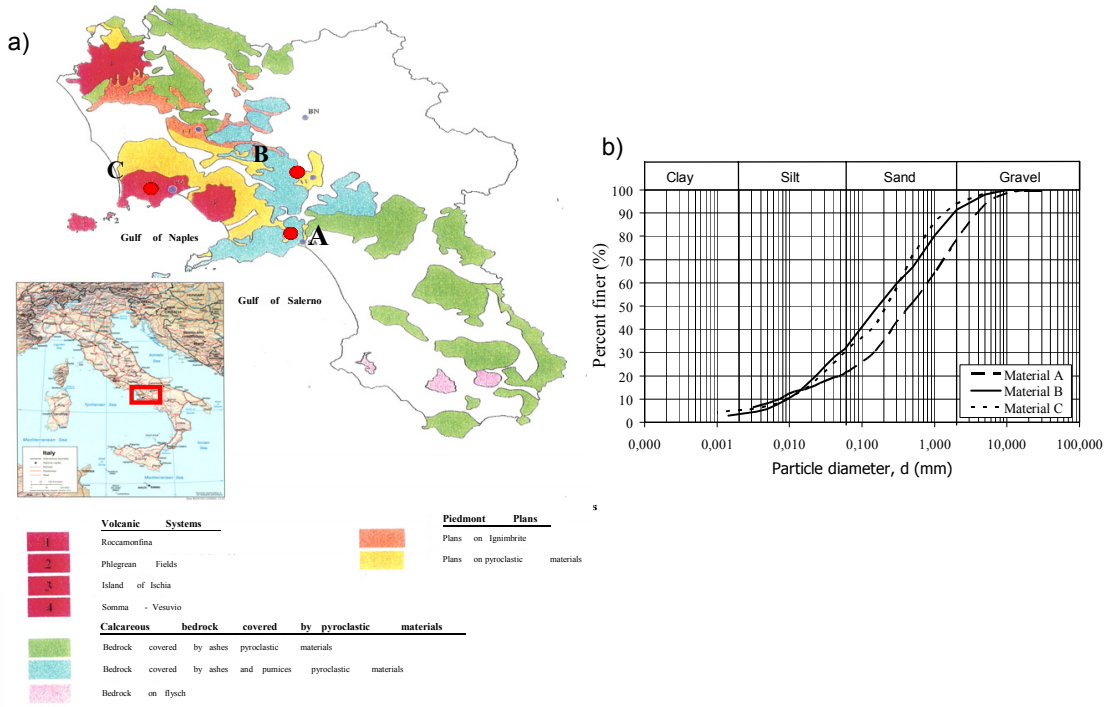

Figure 3: a) Location of the studied debris flows and distribution of the main pyroclastic deposits; b) Grain size distribution of the tested debris flow materials.

The experimental program performed is shown in Table 2.

Table 2: $\quad$ Experimental programme.

\begin{tabular}{|c|c|c|c|c|}
\hline$\#$ & Material & Geometry system & $\mathrm{Cv}(\%)$ & Test \\
\hline 1 & \multirow{4}{*}{ A } & \multirow{3}{*}{ PP } & 0.20 & $\mathrm{~A}-0.20-\mathrm{PP}$ \\
\hline 2 & & & 0.30 & $\mathrm{~A}-0.30-\mathrm{PP}$ \\
\hline 3 & & & 0.40 & $\mathrm{~A}-0.40-\mathrm{PP}$ \\
\hline 4 & & VR & 0.20 & $\mathrm{~A}-0.20-\mathrm{VR}$ \\
\hline 5 & \multirow{4}{*}{ B } & \multirow{2}{*}{ PP } & 0.20 & $\mathrm{~B}-0.20-\mathrm{PP}$ \\
\hline 6 & & & 0.30 & $\mathrm{~B}-0.30-\mathrm{PP}$ \\
\hline 7 & & \multirow{2}{*}{ VR } & 0.20 & $\mathrm{~B}-0.20-\mathrm{VR}$ \\
\hline 8 & & & 0.30 & $\mathrm{~B}-0.30-\mathrm{VR}$ \\
\hline 9 & \multirow{3}{*}{$\mathrm{C}$} & \multirow{3}{*}{ VR } & 0.20 & $\mathrm{C}-0.20-\mathrm{VR}$ \\
\hline 10 & & & 0.30 & $\mathrm{C}-0.30-\mathrm{VR}$ \\
\hline 11 & & & 0.40 & $\mathrm{C}-0.40-\mathrm{VR}$ \\
\hline
\end{tabular}

\section{Experimental results}

\subsection{Preliminary evaluations}

Disturbing effects due to material properties and rheometrical geometry features could leading to erroneous data interpretation $[6,10,13,17]$. Depending on the geometry apparatus, shear conditions (related to samples volume) and disturbing effects (related to geometry features and fluid types) change in a different way. 
Data obtained by different facilities should be in agreement only if the material tested has been homogeneously sheared, in each geometry, as predicted by theory $[6,10]$. In order to understand how the geometry system influences the experimental results, preliminary tests on a typical Newtonian fluid, liquid paraffin on sale, have been carried out with facilities, parallel plates and vane rotor. In order to certify the reproducibility of the test, each test has been repeated three times and the averaged values of the experimental results have been considered. Fig. 4 reports the flow curves of the liquid paraffin analyzed obtained using the two mentioned geometries. A quantitatively difference between the experimental results obtained using the parallel plates system and the experimental data obtained using the vane rotor system has always been noted. Comparing the theoretical viscosity $(0.01 \mathrm{~Pa} \cdot \mathrm{s})$ and the measured viscosity values, an overestimate of the rheological parameters has been observed when the parallel plates geometry has been used.

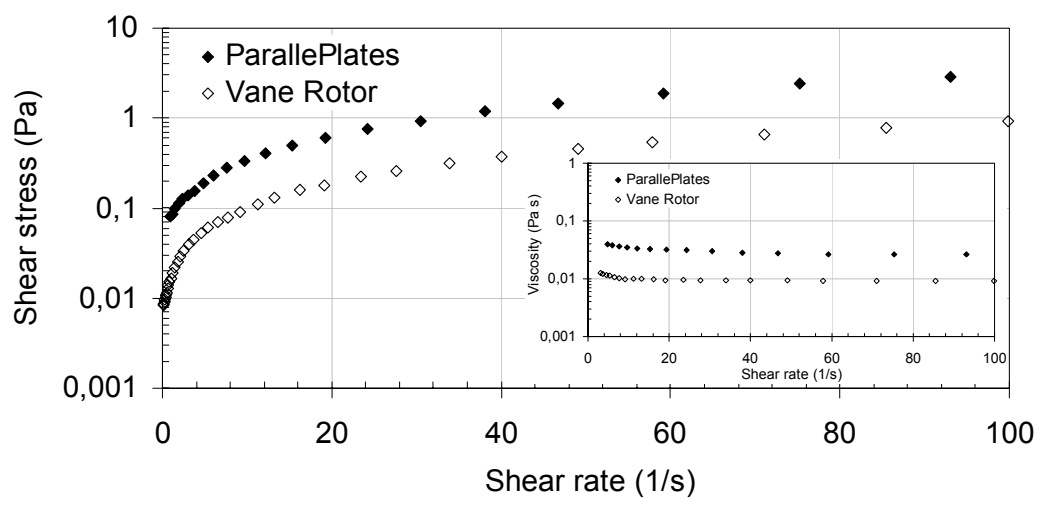

Figure 4: Liquid paraffin on sale. Comparison of parallel plates results and vane rotor results.

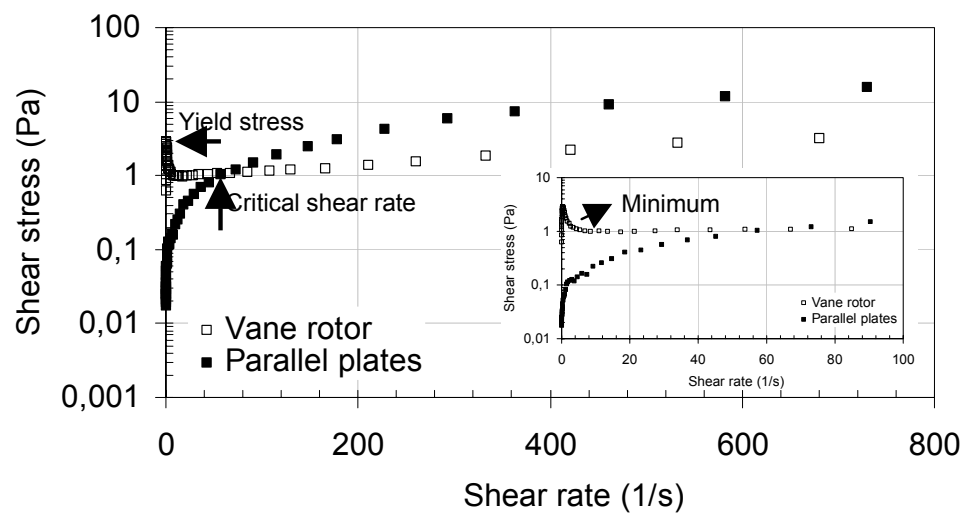

Figure 5: Material $\mathrm{A}, \mathrm{Cv}=0.20$. Comparison between the experimental results obtained with the parallel plates and the vane rotor system. 
Considering the Newtonian behaviour of the liquid paraffin $(\tau=\eta \cdot \dot{\gamma}$ with $\eta=\cos t$ ), a scale factor to go from the results obtained with the parallel plates system to the results obtained with the vane rotor system has been evaluated. For a Non-Newtonian fluid like the mixtures tested, quantitative and qualitative differences have been observed. In fig. 5 for material $\mathrm{A}$ with $\mathrm{C}_{\mathrm{v}}$ equal to 0.20 , the flow curves obtained with the two geometric facilities have been reported. At small shear rate, a minimum in the flow curves attained from the tests carried out using the vane rotor system have been noted: the shear stress decrease with shear rate, followed by a subsequent increase at larger shear rate values. Such a minimum for concentrated suspensions has been reported by several authors and only the increasing part of the flow curves has been considered $[6,10,15,17$, 23-25]. The vane rotor response is higher than the parallel plates response after a shear rate value equal to $50 \mathrm{~s}^{-1}$, which called the critical shear rate (fig. 5). The critical shear rate is about constant for the materials tested and the solid volumetric concentrations considered. After the critical shear rate, the mixtures analyzed behave like a Newtonian fluid according to fig. 4. A scale factor similar to that used for the experimental data of the liquid paraffin has been considered and the flow curves obtained with the parallel plates system have been scaled by this factor. Probably, some disturbing effects have been occurred during the tests like changing of the material free surface, edge/crack effects, heterogeneities in particle distribution (particle settling and migration due to particle inertia and secondary flow) and the phenomenon of wall slip. The occurrence of some disturbing effects has been evaluated. Sedimentation certainly occurred because the difference $\Delta \rho$ between the densities of the disperse phase $\rho_{d}$ and the continuous phase $\rho_{c}$ is greater than $10^{3}$ [26], as shown following:

$$
\Delta \rho=\rho_{d}-\rho_{c}=2600-1000=1.6 \cdot 10^{3} \frac{\mathrm{kg}}{\mathrm{m}^{3}}>10^{3} \frac{\mathrm{kg}}{\mathrm{m}^{3}}
$$

Particle inertia occurred because the particle Reynolds number $R e_{P}$ is greater than $10^{-1}$ [27], as shown following:

$$
\operatorname{Re}_{p}=\frac{\rho_{c} \cdot \dot{\gamma} \cdot a^{2}}{\eta_{c}}=\frac{1000 \cdot 50 \cdot 0.05^{2}}{10^{-3}}=12.5 \cdot 10^{-1}>10^{-1}
$$

It is possible to estimate the influence of settling through the calculation of the experimental time $t_{\text {exp }}$ required for a single sphere to migrate over a length $l(l$ is equal to $H$, the gap height) as shown following:

$$
t_{\text {exp }}=\frac{9}{2} \cdot \frac{\eta_{c} \cdot l}{\Delta \rho \cdot g \cdot a^{2}}=\frac{9}{2} \cdot \frac{10^{-3} \cdot 1}{1600 \cdot 9.81 \cdot 0.05^{2}}=0.115 \mathrm{sec}
$$

where $\Delta \rho=|\rho d-\rho c|, g$ is the acceleration of gravity and $a$ is the radius of the particle with maximum size in the mixtures [27].

In the following the flow curves for shear rate more than the critical shear rate have been shown. 


\subsection{Experimental results and model fitting}

In fig. 6 the experimental data and the theoretical flow curves in a semi logarithmic scale diagram for each material analyzed, at different solid volumetric concentration $\mathrm{C}_{\mathrm{v}}$, have been reported: the solid line represents the theoretical model function and the points indicate the experimental data. The best fitting model of the experimental data is the theoretical model of Bingham. The model fitting parameters have been reported in Table 3. First of all, it is noted that, after the critical shear rate, all the debris flow mixtures investigated behave like a shear-thinning yield stress fluids: shear stress increases with the increase of shear rate and the viscosity decreases. The influence of the solid volumetric concentration $\mathrm{C}_{\mathrm{v}}$ on the rheological parameter of debris flow material mixtures tested has been evaluated. Proportionally higher values of shear stress and viscosity with increasing of the solid volumetric concentration have been noted. Moreover, on equal solid volumetric concentration, the yield stress and the viscosity of material $\mathrm{B}$ are higher than the yield stress and the viscosity of materials $\mathrm{A}$ and $\mathrm{C}$. The rheological parameters of material $\mathrm{C}$ are the lowest according to the volcanic particle nature.

Table 3: $\quad$ Bingham model parameters.

\begin{tabular}{|c|c|c|c|c|}
\hline \multirow{2}{*}{ Material } & $\begin{array}{c}\mathrm{CV} \\
(\%)\end{array}$ & $\begin{array}{c}\tau_{\mathrm{y}} \\
(\mathrm{Pa})\end{array}$ & $\begin{array}{c}\eta_{\mathrm{B}} \\
(\mathrm{Pa} \cdot \mathrm{s})\end{array}$ & $\mathrm{R}^{2}$ \\
\hline \multirow{3}{*}{$\mathrm{A}$} & 0.20 & 0.732 & 0.0037 & 0.998 \\
\cline { 2 - 5 } & 0.30 & 0.927 & 0.0059 & 0.999 \\
\cline { 2 - 5 } & 0.40 & 1.337 & 0.0233 & 0.999 \\
\hline \multirow{3}{*}{$\mathrm{B}$} & 0.20 & 3.792 & 0.0145 & 0.991 \\
\cline { 2 - 5 } & 0.30 & 16.88 & 0.0333 & 0.969 \\
\hline \multirow{3}{*}{$\mathrm{C}$} & 0.20 & 0.047 & 0.0033 & 0.999 \\
\cline { 2 - 5 } & 0.30 & 0.181 & 0.0042 & 0.998 \\
\cline { 2 - 5 } & 0.40 & 0.607 & 0.0074 & 0.999 \\
\hline
\end{tabular}

In fig. 7 the yield stress $\tau_{y}$ (obtained by the results of the vane rotor) versus the solid volumetric concentration $\mathrm{C}_{\mathrm{v}}$ has been reported: the yield stress $\tau_{y}$ exponentially increase with the increase of solid volumetric concentration $\mathrm{C}_{\mathrm{v}}$. According to some previous study [4-6, 10, 12, 13, 17], the following relation could be used:

$$
\tau_{y}=\alpha \cdot e^{\beta \cdot C_{v}}
$$

where $\alpha$ and $\beta$ are fitting parameters. Their values have been reported in table 4 .

Table 4: $\quad$ Fitting parameters $\alpha$ and $\beta$.

\begin{tabular}{|c|c|c|}
\hline Material & $\alpha$ & $\beta$ \\
\hline A & 0,2464 & 0,1215 \\
\hline B & 0,1333 & 0,1909 \\
\hline C & 0,0089 & 0,1066 \\
\hline
\end{tabular}



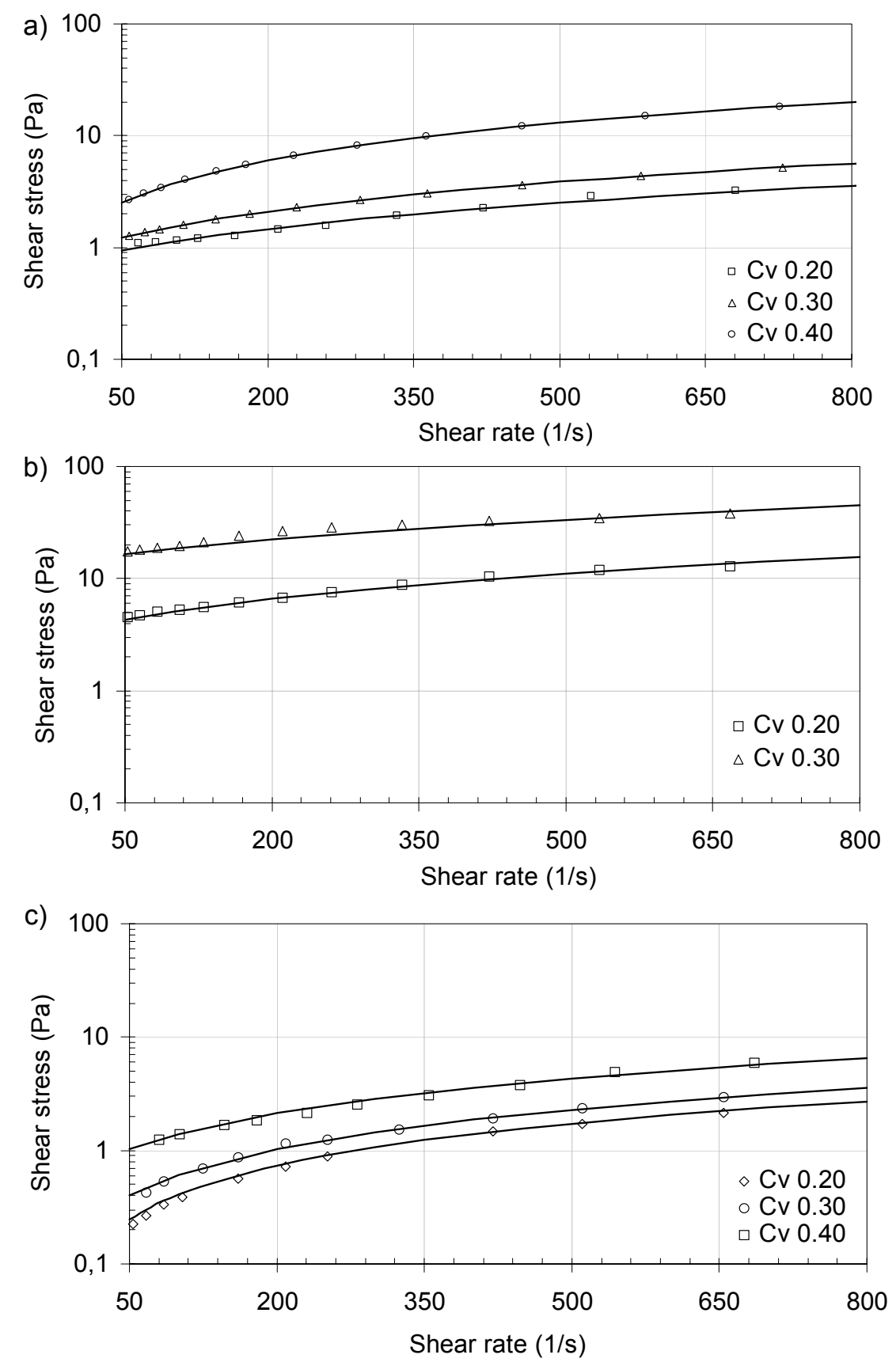

Figure 6: Experimental data and theoretical flow curves at different volumetric concentration $\mathrm{C}_{\mathrm{v}}$ : a) material $\mathrm{A}$; b) material $\mathrm{B}$; c) material $\mathrm{C}$. 


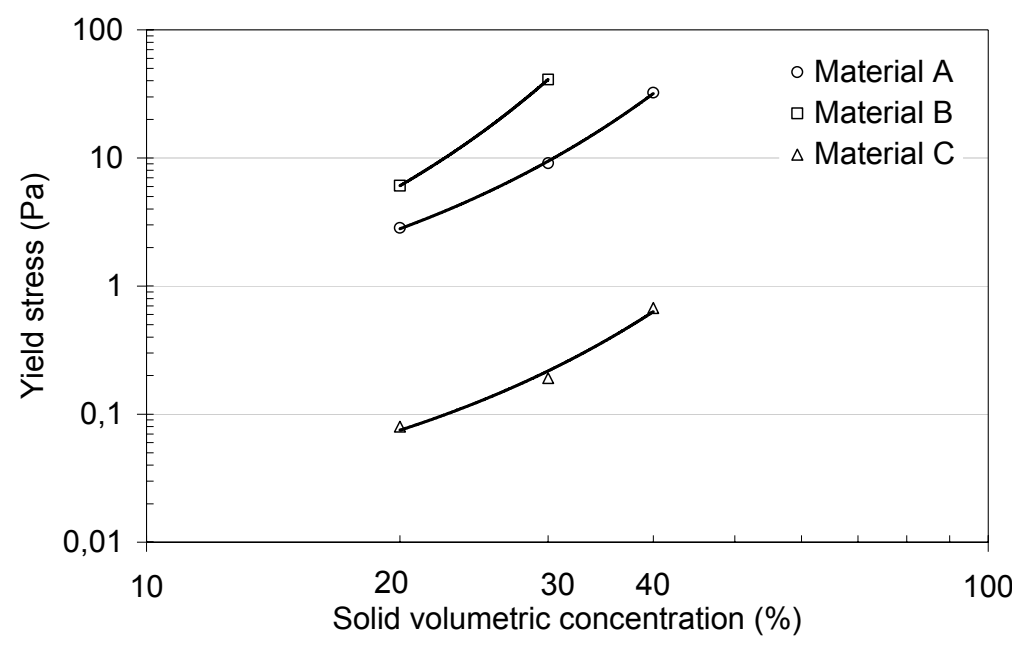

Figure 7: $\quad$ Yield stress $\tau_{\mathrm{y}}$ versus solid volumetric concentration $\mathrm{C}_{\mathrm{v}}$.

\section{Conclusion}

In order to evaluate the rheological behaviour of natural debris flow material, laboratory tests involving soils taken from the source area of three debris flows occurred in Campania region (southern Italy) have been carried out. Mixtures with varying concentration of fine sediment with maximum diameter less than $0.1 \mathrm{~mm}$ and distilled water have been prepared. The debris flow mixtures have been investigated in a standard rheometer with two different geometries, the parallel plates system and the vane rotor system. The vane geometry seems to be an appropriate rheometrical tool for quantitative evaluation of the rheological behaviour of debris flow materials (but using the parallel plates system is also possible to give some simple qualitative ideas about debris flow mixtures). The comparison between two geometry configurations allows checking the range of shear rate where there are not disturbing effects and misleading evaluations. In this range of shear rate all the debris flow mixtures tested behave like a shear thinning yield stress fluid: shear stress increases with the increase of shear rate and viscosity decreases when increasing shear rate. These experimental data have been fitted with the theoretical Bingham model. The increase in solid volumetric concentration produces an increase of shear stress and viscosity. The yield stress dependent exponentially on the solid volumetric concentration. The experimental results presented have to be preliminary, because they have been carried out only on particles less than $0,1 \mathrm{~mm}$. For determining the rheological behaviour of gravel-sand mixtures, new apparatus have been set up.

\section{References}

[1] Costa, J.E. \& Williams, G.P., Debris flow dynamics (videotape), US Geological Survey Open file 84 - 606, 22min, 1984. www. pubs.usgs.gov/of/1984/ofr84-606/ 
[2] Johnson, A.M., Debris flow. Topics in Slope Instability, eds. D. Brunsden and D.B. Prior, Wiley, New York, pp. 257-361, 1984.

[3] Coussot, P. \& Piau, J.M., On the behaviour of fine mud suspensions. Rheologica Acta, 33, pp. 175-184, 1994.

[4] O'Brien, J.S. \& Julien, P.Y., Physical properties and mechanics of hyperconcentrated sediment flow. Proc. of the Specialty Conference on Delineation of landslide, flash flood and debris flow hazard in Utah, Utah Water Research Laboratory, General Series, UWRL/G-85/03, pp. 260278., 1984.

[5] Phillips, C.J. \& Davies, T.R.H., Determining rheological parameters of debris flow material. Geomorphology, 4, pp. 573-587, 1991.

[6] Major, J.J. \& Pierson, T.C., Debris flow rheology: experimental analysis of fine - grained slurries. Water Resources Research, 28 (3), pp. 841-857, 1992.

[7] Savage, S.B. \& Hutter, K., The motion of a finite mass of granular material down a rough incline. Journal of Fluid Mechanics, 199, pp. 177215, 1989.

[8] Iverson, R.M., The physic of debris flow. Reviews of Geophysics, 35, pp. 245-296, 1997.

[9] Takahashi, T., Debris flow Mechanics, Prediction and Countermeasures, Taylor and Francis Group: London, pp. 35-38, 2007.

[10] Coussot, P., Mudflow Rheology and Dynamics, IAHR Monograph Series, A.A. Balkema: Rotterdam, pp. 252, 1997.

[11] Bagnold, R.A., Experiment on a gravity-free dispersion of large solid sphere in a Newtonian fluid under shear. Proc. of The Royal Society London, Series A, pp. 49-63, 1954.

[12] O'Brien, J.S. \& Julien, P.Y., Laboratory analysis on mudflow properties. Journal of Hydraulic Engineering, 144, pp. 877-887, 1988.

[13] Coussot, P. \& Piau, J.M., A large-scale field cylinder rheometer for the study of the rheology of natural coarse suspensions. Journal of Rheology, 39 (1), pp. 105-123, 1995.

[14] Contreras, S.M. \& Davies, T.H.R., Coarse-Grained Debris Flows, Hysteresis and Time-Dependent Rheology. Journal of Hydraulic Engineering, 126, pp. 938-941, 2000.

[15] Ancey, C. \& Jorrot, H., Yield stress for particle suspensions within a clay dispersion. Journal of Rheology, 45 (2), pp. 297-319, 2001.

[16] Schatzmann, M., Rheometry of large particle fluids and debris flows, $\mathrm{PhD}$ Dissertation No 16093, ETH, Zürich, Switzerland, pp. 192, 2005.

[17] Kaitna, R., Rickenmann, D. \& Schatzmann, M., Experimental study on rheological behaviour of debris flow material, Acta Geotechnica, 2, pp. 71-85, 2007.

[18] Nguyen, Q.D. \& Boger, D.V., Measuring the flow properties of yield stress fluids, Annual Review of Fluid Mechanics, 24, pp. 47-88, 1992.

[19] Chhabra, R.P. \& Richardson, J.F., Non-Newtonian Flow in the Process Industries. Butterworth-Heinemann. Oxford, pp 436, 1999. 
[20] Scotto di Santolo, A., Analisi geotecnica dei fenomeni franosi nelle coltri piroclastiche della provincia di Napoli, $\mathrm{PhD}$ thesis, University of Naples "Federico II" and Rome "La Sapienza", 2000.

[21] Ruopolo, S., Analisi dei fenomeni franosi nella coltre piroclastica non satura del cratere degli Astroni, Graduate thesis, Department of Geotechnical Engineering, University of Naples "Federico II", 2006.

[22] Papa, R., Indagine sperimentale di una copertura piroclastica di un versante della Campania, PhD thesis, University of Naples "Federico II", 2007.

[23] Alderman, N.J., Meeten, G.H. \& Sherwood, J.D., Vane rheometry of bentonite gels, Journal of Non-Newtonian Fluids Mechanics, 39, pp. 291310, 1991.

[24] Nguyen, Q.D. \& Boger, D.V., Direct yield stress measurement with the vane method, Journal of Rheology, 29, pp. 335-347, 1985.

[25] Pignon, F., Magnin, A. \& Piau, J.M., Thixotropic colloidal suspension and flow curve with a minimum: identification of flow regimes and rheometric consequence, Journal of rheology, 40, pp. 573-587, 1996

[26] Larson, R.G., The Structure and Rheology of Complex Fluids. Oxford Univ. Press, New York, 1999.

[27] Macosko, C.W., Rheology. Principles, Measurements and Applications. Wiley-VCH, Inc. pp 550.1994 